\title{
Ensaios de arrancamento e de empuxamento aplicados a taliscas de bambu encravadas em corpos-de-prova de solo-cimento
}

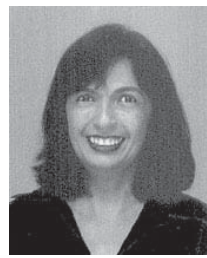

Wilza G. R. Lopes ${ }^{1}$, Wesley J. Freire ${ }^{2}$ \& Gisleiva C. dos S. Ferreira ${ }^{3}$

1 FEAGRI/UNICAMP. Rua Major Manoel Lopes 1714, Morada do Sol, Teresina, PI. CEP 64056-570. Fone: (86) 2331274. E-mail: izalopes@uol.com.br (Foto)

2 FEAGRI/UNICAMP, CP 6011, CEP 13083-970, Campinas, SP. Fone: (19) 3788 1040. E-mail: wesley@agr.unicamp.br

3 Técnica de Laboratório - FEAGRI/UNICAMP, Campinas, SP. E-mail: gisleiva@agr.unicamp.br

Protocolo $25-26 / 2 / 2002$

Resumo: Neste trabalho, taliscas de bambu da espécie Dendrocalamus giganteus, engastadas em corpos-de-prova de solo-cimento, foram submetidas a ensaios de arrancamento (pull-out) e de empuxamento (push-out) a fim de se determinar sua resistência de aderência. Para esta finalidade, foi utilizado um solo-cimento feito a partir de um solo arenoso que continha aproximadamente $70 \%$ de areia. Corpos-de-prova de solo-cimento, de $15 \mathrm{~cm}$ de diâmetro e $30 \mathrm{~cm}$ de altura, foram moldados com $14 \%$ de cimento na umidade ótima de $10,7 \%$. As taliscas de bambu foram preparadas com $2 \mathrm{~cm}$ de largura e comprimentos de 40, 50 e $60 \mathrm{~cm}$, para o ensaio de arrancamento, e de $70 \mathrm{~cm}$ para o ensaio de empuxamento. Metade das taliscas foi deixada sem tratamento impermeabilizante e a outra metade foi revestida com emulsão asfáltica, impregnada com areia limpa grossa, para produzir uma superfície áspera e garantir melhor aderência com o solo-cimento. Os corpos-de-prova de solo-cimento com as taliscas de bambu engastadas, foram deixados a curar em câmara úmida, durante $28 \mathrm{~d}$, antes de serem ensaiados. Ambos os ensaios foram realizados em uma máquina universal de ensaio adaptada, sendo as deformações medidas com um relógio comparador aferido, de sensibilidade igual a 0,01 $\mathrm{mm}$. A resistência de aderência, quer fosse determinada pelo ensaio de arrancamento quer pelo ensaio de empuxamento, foi obtida dividindo-se a máxima carga verificada no ensaio pela área lateral da talisca de bambu efetivamente engastada no solo-cimento. Os melhores resultados foram obtidos sem aplicação de material impermeabilizante, para o ensaio de arrancamento, enquanto nenhuma diferença foi observada entre os dois tratamentos para o ensaio de empuxamento.

Palavras-chave: solo-cimento, bambu, aderência, arrancamento, empuxamento

\section{Pull-out and push-in tests of bamboo splint embedded in soil-cement specimen}

\begin{abstract}
In this study, Dendrocalamus giganteus bamboo splints (split culm) embedded in soilcement specimens were submitted to pull-out and push-in tests in order to determine its bonding strength. For this purpose a sandy soil was utilized. The $15.0 \mathrm{~cm}$ diameter and $30.0 \mathrm{~cm}$ high soil-cement specimens were moulded with $14 \%$ cement at $10.7 \%$ optimum moisture. Bamboo splints were manually prepared to have precisely $2 \mathrm{~cm}$ width and 40.0,50.0, and $60.0 \mathrm{~cm}$ lengths and embedment depths of $10.0,20.0$, and $30.0 \mathrm{~cm}$, respectively. The bamboo splints were divided in two groups: the first group comprising of splints with no waterproofing treatment, and the second group consisted of seasoned (dry) splints with asphalt emulsion sprinkled with coarse clean sand to produce a rough surface and to insure positive bond with soil-cement. The bond strength was determined by dividing the ultimate pull-out load by the embedded bamboo splint's lateral area. The experimental data were statistically analyzed and the treatments were applied in three replications. The best results were obtained for control condition (bamboo splint without asphalt emulsion coat and coarse sand sprinkling) in the pull-out test. No statistical difference was found between the treatments in the push-in test.
\end{abstract}

Key words: soil-cement, bamboo, bonding, pull-out, push-in 


\section{INTRODUÇÃO}

O bambu é uma gramínea perene, conhecida pelo homem desde os tempos pré-históricos e utilizada como material de construção, alimento, arma e muitos outros utensílios domésticos. É, também, amplamente encontrado em quase todas as zonas tropicais, subtropicais e muitas zonas temperadas, caracterizando-se por apresentar elevada resistência à tração, alta relação resistência/peso, além de baixo custo da matériaprima.

Recht \& Wetterwald (1994) relataram que o uso do bambu no continente asiático é bastante disseminado na construção de casas, na confecção de utensílios domésticos e de implementos agrícolas, como ração animal, na alimentação humana e, ainda, como medicamento. No setor da construção civil seu uso é bastante difundido na Ásia e em vários países da América Latina, como: Peru, Equador, Costa Rica e Colômbia, onde vários exemplos de edificações confirmam sua potencialidade. Assim, Janssen (1995) destacou que é comum o uso do bambu em construções populares, e que, em países como Costa Rica e Japão, são encontrados exemplos de edificações de alto padrão comprovando, mais uma vez, sua potencialidade como material de construção. Ghavami (1992), estudando a relação entre resistência a tração e o peso específico de alguns materiais de construção, constatou que o bambu é o material que apresenta valor maior para esta relação, o que o torna vantajoso como material de construção.

Dentre as espécies mais utilizadas, no setor da construção civil, destaca-se o Dendrocalamus giganteus, que apresenta rápido crescimento e resistência mecânica considerável. Esta espécie, de origem asiática, é encontrada em quase todas as regiões do Brasil, sendo mencionada como uma das maiores existentes no mundo.

Segundo Geymayer \& Cox (1970), a idéia de se usar bambu como reforço para o concreto remonta a anos anteriores a 1940. Desde então, as pesquisas mostraram a viabilidade do uso do bambu para tal finalidade identificando, também, problemas relacionados com a aderência, variações volumétricas e possível degradação.

Em se tratando de material composto, a eficaz aderência dentre os diversos materiais envolvidos, é um fator primordial para o bom desempenho do produto. Neste sentido, Leonhardt \& Mönnig (1977) afirmaram que o concreto armado deve suas boas características de material de construção à firme ligação por aderência entre o concreto e as barras da armadura. Por meio da aderência garante-se que as barras de armadura, como um todo, apresentam um alongamento igual ao das fibras vizinhas do concreto armado.

O bambu, ao ser usado como reforço de concretos, absorve a água da mistura, aumentando de volume e voltando às dimensões originais após secagem. Isto faz com que a aderência entre os dois materiais fique prejudicada. A susceptibilidade do bambu, à mudança de volume na presença de água, é considerada como a mais séria desvantagem para seu uso, como reforço do concreto. Na tentativa de minimizar os efeitos da absorção de água pelo bambu, alguns métodos têm sido estudados e empregados por pesquisadores.

Ghavami \& Hombeek (1981) testaram 15 produtos para reduzir a absorção de água pelo bambu, e, dentre os quais, a cera e o epóxi foram os que apresentaram menor absorção de água, porém não foram considerados apropriados, devido ao alto custo e à baixa resistência de aderência.

Beraldo (1987) indicou que, antes da concretagem, para se evitar a variação dimensional das peças de bambu em presença da umidade, deve-se recorrer à pré-saturação parcial ou à impermeabilização, seguida de jateamento de areia.

Kurian \& Kalam (1977) testaram a aplicação de três camadas de uma solução de $40 \%$ de resina solúvel em álcool, seguida de uma de mão de zarcão (óxido de chumbo); já Ghavami (1992), em ensaios de lajes de concreto com forma permanente de bambu, empregou colmos de bambu abertos e tratados internamente com pintura e areia, e colmos de bambu que foram imersos em água por $48 \mathrm{~h}$ antes de serem utilizados.

Argollo Ferrão \& Freire (1995) utilizaram, em estudos com taliscas de bambu da espécie Bambusa tuldoides, visando aumentar a aderência entre o bambu e o concreto, diversos tratamentos, como imersão em piche quente e salpicadura com areia média; cravejamento de grampos de cerca; fretagem com arame farpado esticado e pregado, e ranhuras executadas com $2,5 \mathrm{~cm}$ de passo. Posteriormente, foram as mesmas encravadas no concreto ainda fresco, nas profundidades de ancoragem de 10,20 e $30 \mathrm{~cm}$, e deixadas em repouso por $48 \mathrm{~h}$. Após a desmoldagem, os corpos-de-prova foram curados durante $28 \mathrm{~d}$, em imersão completa, sendo então submetidos a ensaios de arrancamento (pull-out test). Os resultados mostraram que taliscas de bambu engastadas a 20 e $30 \mathrm{~cm}$ de profundidade, desenvolveram maior aderência que aquelas engastadas a 10 $\mathrm{cm}$, embora sem diferirem significativamente, independente do tratamento aplicado. Da mesma forma e se considerada a relação entre força de arrancamento e área superficial das taliscas de bambu encravadas, não se constataram diferenças significativas entre os tratamentos, do ponto de vista do aumento de aderência, independentemente do tratamento aplicado ou da profundidade de ancoragem considerada.

Lima Jr. et al. (1996) realizaram ensaios de empuxamento para avaliar a resistência de aderência do bambu ao concreto. Taliscas de bambu da espécie Dendrocalamus giganteus foram pré-tratadas com materiais impermeabilizantes (asfalto e Negrolin) e encravadas em blocos de concreto fresco, a determinada profundidade. Neste ensaio, ao contrário do ensaio de arrancamento, aplica-se uma pressão de compressão na talisca de bambu, até que ocorra deslocamento de $4 \mathrm{~mm}$ da extremidade livre do colmo, em relação ao concreto, correspondendo o deslocamento de $0,1 \mathrm{~mm}$ à tensão de aderência, que permitirá obter a resistência de aderência. Ao final, os autores concluíram que os bambus tratados com os materiais impermeabilizantes estudados mobilizaram pequenas tensões de aderência, sendo as taliscas de bambu, com nó e sem qualquer tratamento, as que apresentaram maior resistência ao deslizamento.

Embora o bambu seja muito resistente à tração, a completa mobilização de sua resistência à tração, todavia, raramente é possível de ser obtida, devido à baixa aderência desenvolvida entre o bambu e o solo-cimento. Para superar esta dificuldade, Kurian \& Kalam (1977) relataram várias técnicas desenvolvidas com a finalidade de melhorar a adesão entre o bambu e o solocimento, avaliando-se a eficiência dessas técnicas, através de 
ensaios de arrancamento. Os resultados mostraram, segundo aqueles autores, que os corpos-de-prova submetidos a um tratamento impermeabilizante, que incluía aplicações superficiais com uma solução de $40 \%$ de uma resina diluída em álcool, seguidas de uma única aplicação de zarcão (pintura à base de chumbo) desenvolveram boa aderência, melhorada ainda mais, quando da ocorrência de nós dispensando, assim, quaisquer outras técnicas especiais utilizadas para a mesma finalidade.

Com o objetivo de verificar a aderência entre o bambu e o concreto, Salgado (2000) comparou diversos tratamentos empregados em taliscas de bambu encravadas em concreto, por meio de ensaios de arrancamento. Foram utilizadas taliscas sem tratamento, taliscas com alcatrão e areia, taliscas envolvidas em arame farpado, taliscas com grampos de cerca e, também, com ranhuras na casca; todos estes métodos são considerados baratos e fáceis de se aplicar. $\mathrm{O}$ autor concluiu, então, que o tratamento que apresentou maior resistência à aderência, em relação às forças de arrancamento aplicadas, foi o do alcatrão com areia, seguido de grampo de cerca e de arame farpado.

Este trabalho se destinou a avaliar a resistência de aderência e a força de arrancamento do bambu ao solo-cimento, em dois tipos de ensaio ('pull-out' ou arrancamento, e 'push-in' ou empuxamento), usando-se taliscas de bambu Dendrocalamus giganteus, não-tratadas e tratadas com emulsão asfáltica, engastadas em corpos-de-prova de solo-cimento.

\section{MATERIAL E MÉTODOS}

\section{Coleta e preparação do bambu}

Para coleta, tratamento e preparo das taliscas de bambu e do solo-cimento utilizados na confecção dos corpos-de-prova de solo-cimento reforçados com bambu, foram usados os mesmos procedimentos, tanto para o ensaio de arrancamento como para o de empuxamento.

Empregou-se a espécie de bambu Dendrocalamus giganteus, cujos colmos foram retirados de touceiras uniformes, colhidos na Fazenda Santa Elisa, do Instituto Agronômico de Campinas, na cidade de Campinas, Estado de São Paulo. Para a coleta dos colmos, foram escolhidas touceiras sujeitas às mesmas condições agronômicas de cultivo, supondo-se que fossem idênticas. Os colmos foram selecionados ao acaso, com idade superior a três anos e cortados no mesmo dia, com a utilização de moto-serra, para o corte, e facão para a retirada das brotações.

Logo após o corte, os colmos foram transportados para a Faculdade de Engenharia Agrícola e deixados submersos em água por $7 \mathrm{~d}$ para, através do processo de fermentação, eliminar parte do amido, responsável pelo ataque de caruncho e de insetos. Após este período, os colmos foram submetidos ao tratamento químico, que consistiu na sua colocação em tambores metálicos, em solução de $1,5 \mathrm{~kg}$ de sulfato de cobre, mais $1,5 \mathrm{~kg}$ de dicromato de sódio, dissolvidos em $100 \mathrm{~L}$ de água. Após este tratamento, os colmos foram secados à sombra, por um período de $30 \mathrm{~d}$.

O bambu foi cortado transversalmente, em serra circular, e longitudinalmente com faca e, depois, regularizado com auxílio de uma plaina, produzindo taliscas nas dimensões pré-determinadas para cada ensaio.

Para o ensaio de arrancamento, foram confeccionadas 18 taliscas com largura de $2 \mathrm{~cm}$ e comprimentos variando de 40, 50 e $60 \mathrm{~cm}$, de acordo com as profundidades de ancoragem empregadas. A espessura das taliscas, quando sem tratamento, variou entre 0,8 e $1,3 \mathrm{~cm}$, conforme a característica de cada colmo.

Para o ensaio de empuxamento, seis taliscas de bambu foram cortadas com largura de $2 \mathrm{~cm}$ e comprimento de $70 \mathrm{~cm}$. Suas espessuras apresentaram variação entre 6,60 e 8,65 mm, antes da aplicação do tratamento com emulsão asfáltica e areia.

Em ambos os casos, foram realizadas seis medições da espessura e três da largura das taliscas, com auxílio de um paquímetro digital, Starret, de sensibilidade 0,01 mm. As médias dessas medidas foram consideradas, respectivamente, como sendo os valores da espessura e da largura das taliscas de bambu.

\section{Solo-cimento}

Para a obtenção da mistura solo-cimento, foi usado um solo com características predominantemente arenosas, com 72,5\% de areia, $13,0 \%$ de silte e 14,5\% de argila, coletado em jazida localizada no Município de Sumaré, São Paulo. Utilizou-se o cimento Portland CP II-E-32 NBR 11578 da ABNT (1991) na proporção de $14 \%$, em massa e se adotaram os valores de $10,75 \%$ para o teor de umidade ótima e de $1,95 \mathrm{~kg} \mathrm{dm}^{-3}$ para massa específica aparente seca máxima, conforme resultados do ensaio de compactação, realizado anteriormente.

Com a mistura de solo-cimento foram moldados corpos-deprova em fôrmas metálicas cilíndricas, de diâmetro igual a 15 $\mathrm{cm}$, por $30 \mathrm{~cm}$ de altura, utilizando-se o mesmo soquete de Proctor e a mesma energia de compactação normal, tendo sido o solo-cimento colocado em seis camadas aplicando-se, em cada uma delas, 69 golpes de soquete. Após a colocação da última camada, fez-se o nivelamento com régua metálica. Dois dias após a moldagem, os mesmos foram desmoldados e deixados a curar em condições úmidas durante $28 \mathrm{~d}$, antes de serem ensaiados (Fig. 1).

A.

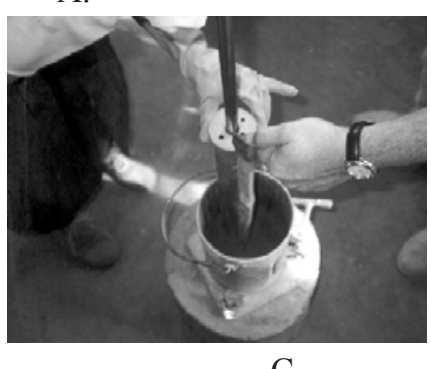

C.
B.
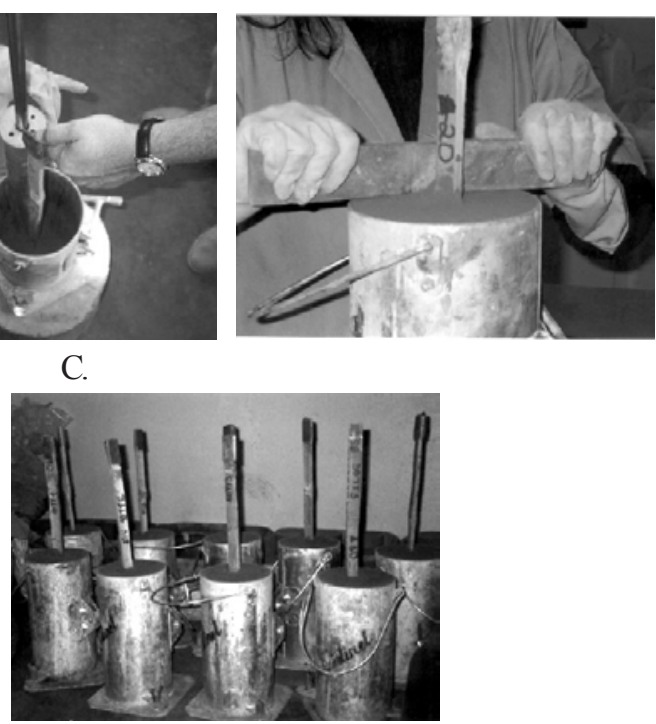

Figura 1. Etapas de compactação (A), nivelamento (B) e processo de cura (C) dos corpos-de-prova para o ensaio de arrancamento 


\section{Tratamentos aplicados}

Foram aplicados dois tratamentos nas taliscas: TT (Testemunha), que correspondia às taliscas de bambu deixadas em seu estado natural, sem tratamento impermeabilizante, e AA (asfalto mais areia) que se referia àquelas taliscas revestidas com emulsão asfáltica, impregnadas com areia limpa grossa. Este procedimento teve a finalidade de reduzir a absorção de água e produzir uma superfície áspera, garantindo melhor aderência com o solo-cimento.

O produto asfáltico utilizado foi o Neutrol 45, tinta betuminosa para concreto, alvenaria e estruturas metálicas, fabricado pela Vedacit, cuja composição básica é asfalto em solvente alifático.

Nos dois tratamentos e também para os dois tipos de ensaio, optou-se pelo uso de taliscas sem nó para a parte encravada no solo-cimento obtendo-se, desta forma, uma situação mais crítica para efeito de aderência, pois os nós atuam de forma positiva para o incremento da aderência, podendo ser obtidos aumentos na resistência à aderência de até $100 \%$, tais como relatados por Ghavami \& van Hombeeck (1981) em ensaios de arrancamento realizados com taliscas de bambu encravadas em corpos-de-prova de concreto.

No ensaio de arrancamento foram consideradas três profundidades de ancoragem: 10,20 e $30 \mathrm{~cm}$, com três repetições cada uma, para cada tratamento, totalizando 18 corpos-de-prova. O procedimento adotado foi aquele descrito por Argollo Ferrão \& Freire (1995), que realizaram ensaios de arrancamento com taliscas de bambu encravadas em corposde-prova de concreto; já para o ensaio de empuxamento, as taliscas foram totalmente encravadas no corpo-de-prova de solo-cimento, ultrapassando $10 \mathrm{~cm}$ na extremidade inferior e 30 $\mathrm{cm}$ na superior. Foram confeccionados seis corpos-de-prova, sendo três sem tratamento e três com tratamento impermeabilizante.

Para a avaliação da aderência, considerou-se apenas o trecho central de $10 \mathrm{~cm}$ da talisca, encravada no corpo-de-prova de solo-cimento. No restante da talisca, a aderência foi reduzida, engraxando-se a talisca (graxa GMA2, para aplicação múltipla, da Lubrax) e enrolando-a com diversas camadas de papel. Esses procedimentos foram sugeridos por Lima Jr. et al. (1996) para concreto reforçado com bambu.

O delineamento experimental foi o inteiramente casualizado, em esquema fatorial $2 \times 3$ (tipos de tratamento $\mathrm{x}$ profundidades) com três repetições, para o ensaio de arrancamento, e três repetições para o de empuxamento, sendo a unidade experimental representada por um corpo-de-prova. No ensaio de arrancamento, para comparação das médias de tratamento (com e sem asfalto) e de profundidades de ancoragem, fez-se análise de variância, aplicando-se o teste Duncan. Para o ensaio de empuxamento o teste utilizado foi o de Tukey (SAS, 1986).

\section{Procedimentos dos ensaios de arrancamento e de empuxa- mento}

Os ensaios de arrancamento e de empuxamento foram realizados em Máquina Universal de Ensaio Dinatest, adotandose velocidade de carregamento de $2 \mathrm{~N} \mathrm{~s}^{-1}$. Para se medir os deslocamentos do bambu, utilizaram-se relógios comparadores, aferidos, de sensibilidade $0,01 \mathrm{~mm}$, fixados com auxílio de base magnética.

Para a fixação dos corpos-de-prova de solo-cimento à maquina de ensaio, foram realizadas algumas adaptações que consistiram na colocação de três chapas metálicas, interligadas por barras de aço roscadas, fixadas com rosca tipo borboleta, que sustentavam o corpo-de-prova de solo-cimento na parte intermediária da prensa, de forma a permanecer completa- mente imóvel durante a aplicação da carga. No ensaio de arrancamento, a garra superior da máquina de ensaio prendia a talisca de bambu, puxando-a para cima e exercendo, assim, uma força de arrancamento, de tal modo a forçar o bambu a se deslocar do solo-cimento (Fig. 2A); já no ensaio de empuxamento o corpode-prova foi fixado do mesmo modo que no ensaio de arrancamento, sendo a talisca de bambu empurrada para cima, pela parte inferior da prensa, provocando também um escorregamento da talisca dentro do solo-cimento (Fig. 2B). A tensão aplicada foi visualizada através do manômetro da prensa e o deslocamento foi obtido com auxílio de relógio comparador, fixado à prensa através de base magnética, onde foram realizadas medidas a cada $1 \mathrm{kN}$ de carga aplicada.

A.

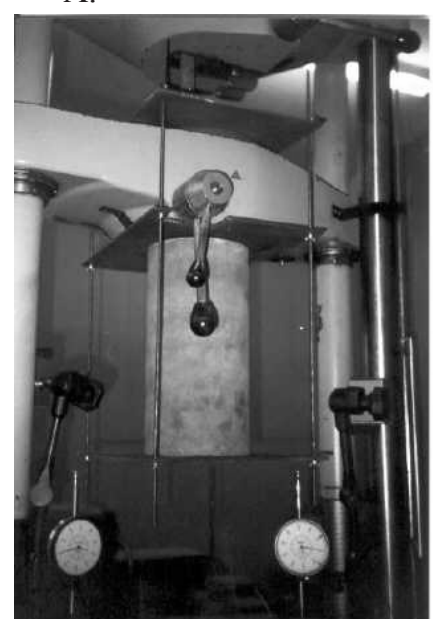

Figura 2. Ensaio de arrancamento (A) e empuxamento (B)

Obteve-se o valor da resistência de aderência pela divisão do valor da força máxima de arrancamento pela área lateral de contato entre o bambu e o solo-cimento, região onde se desenvolve a força de atrito, conforme fórmula abaixo. A área de contato corresponde ao valor do perímetro da área da talisca encravada, multiplicado pela profundidade de ancoragem correspondente $(10,20$ ou $30 \mathrm{~cm})$.

$$
\tau=\frac{\mathrm{P}}{(21+2 \mathrm{e}) \mathrm{h} 10}
$$

em que:

$$
\begin{array}{ll}
\tau & \text { - resistência de aderência, } \mathrm{MPa} \\
\mathrm{P} & \text { - força, kgf } \\
\mathrm{l} & \text { - largura da talisca de bambu, } \mathrm{cm} \\
\mathrm{e} & \text { - espessura da talisca de bambu, cm } \\
\mathrm{h} & \text { - profundidade de ancoragem, } \mathrm{cm}
\end{array}
$$

Da mesma forma que o ensaio de arrancamento, a resistência de aderência no ensaio de empuxamento foi obtida dividindo-se 
a força máxima de arrancamento pela área lateral da talisca de bambu ancorada no solo-cimento, utilizando-se a mesma fórmula anterior, considerando, porém, a altura igual a $10 \mathrm{~cm}$ (comprimento da talisca efetivamente ancorada no solocimento).

\section{RESULTADOS E DISCUSSÃO}

Os dados da resistência ao arrancamento (resistência de aderência) em MPa, das taliscas de bambu encravadas no solo-cimento, em função dos tratamentos aplicados e das profundidades de ancoragem consideradas para o ensaio de arrancamento, estão apresentados na Tabela 1 .

Tabela 1. Resistência ao arrancamento de taliscas de bambu encravadas em solo-cimento (ensaio de arrancamento*)

\section{Resistência ao Arrancamento (MPa)}

Tratamentos Profundidade de Ancoragem (cm)

$10 \quad 20 \quad 30$

Média

\begin{tabular}{lllll}
\hline Com asfalto & $0,94 \pm 0,14$ & $0,84 \pm 0,16$ & $0,52 \pm 0,02$ & $0,77 \pm 0,22 b$
\end{tabular}

Sem asfalto $1,33 \pm 0,15 \quad 1,37 \pm 0,13 \quad 0,74 \pm 0,13 \quad 1,19 \pm 0,31$ a

(TT)

Média

$1,13 \pm 0,25$ a $1,10 \pm 0,32$ a $0,61 \pm 0,14 b$

" Média de 3 repetições, na mesma coluna ou mesma linha, seguidas da mesma letra, não diferem estatisticamente pelo teste de Duncan ( $\mathrm{p}>0,05)$

Constatou-se, na avaliação da resistência de aderência do ensaio arrancamento, que não houve interação $(p>0,05)$ entre os fatores tipos de tratamento (com e sem asfalto) e profundidade de ancoragem $(10,20$ e $30 \mathrm{~cm})$. O valor da resistência foi maior $(\mathrm{p}<0,01)$ nos corpos-de-prova sem asfalto que naqueles em foi utilizada a impermeabilização de emulsão asfáltica mais areia, com valores, respectivamente, de 1,19 e 0,77 MPa.

No ensaio de empuxamento, ao contrário do esperado, à profundidade de ancoragem de $30 \mathrm{~cm}$, tanto para os tratamentos com asfalto (AA) como para os sem asfalto (TT), foram observados valores inferiores aos correspondentes as profundidades de ancoragem de 10 e $20 \mathrm{~cm}(\mathrm{p}<0,05)$ devido ao fato das taliscas de bambu se romperem nos nós, antes mesmo de sofrerem deslizamento.

A hipótese não comprovada mais plausível para explicar tal comportamento é a de que as taliscas de bambu se romperam nos nós porque a resistência de aderência do bambu na matriz de solo-cimento foi maior que a resistência à tração do próprio nó.

Kurian \& Kalam (1977) concluíram, em ensaios de resistência à tração em corpos-de-prova de bambu com nó e sem nó, que o bambu com nó apresentou menor resistência que aquela apresentada pelo bambu sem nó. Toledo \& Barbosa (1990) obtiveram valores de resistência à tração de corpos-de-prova de bambu sem nó de quase o dobro, em relação aos exemplares com nó, para bambus da espécie Dendrocalamus giganteus; já, de acordo com Lima Jr. et al. (2000) a tensão de ruptura à tração do bambu na região do nó, para a mesma espécie, chegou a aproximadamente um terço do valor obtido com o bambu sem nó.

Para taliscas de bambu com largura maior que os $2 \mathrm{~cm}$ utilizados neste ensaio, provavelmente a resistência à tração no nó seria maior evitando, em conseqüência, o rompimento da talisca naquela região, durante o ensaio de arrancamento.

Os resultados da força de arrancamento aplicada em função do tipo de tratamento (com e sem asfalto) e das profundidades de ancoragem $(10,20$ e $30 \mathrm{~cm})$ encontram-se na Tabela 2.

A análise dos dados obtidos da força de arrancamento revelou não haver interação $(p>0,05)$ entre os fatores tipos de tratamento (com e sem asfalto) e as profundidades de ancoragem $(10,20$ e $30 \mathrm{~cm})$. O valor da força aplicada (N) nos corpos-deprova elaborados sem asfalto $(12.425 \mathrm{~N})$ foi superior $(\mathrm{p}<0,01)$ ao dos confeccionados com asfalto $(10.400 \mathrm{~N})$. Com relação à profundidade de ancoragem, constatou-se que o maior valor $(\mathrm{p}<0,05)$ da força de arrancamento foi aquele relacionado à profundidade de $20 \mathrm{~cm}$, e o menor, à de $10 \mathrm{~cm}$. $\mathrm{O}$ valor intermediário, verificado para a profundidade de $30 \mathrm{~cm}$, foi considerado atípico, pelos mesmos motivos já levantados.

As leituras das forças e dos deslocamentos foram obtidas para o estado limite de aderência do bambu no solo-cimento. Em nenhuma das situações estudadas as taliscas foram totalmente arrancadas dos corpos-de-prova nos quais estavam ancoradas.

Na Figura 3 (A, B e C) podem ser vista as curvas de tensão vs deslocamento das taliscas de bambu, encravadas em corposde-prova de solo-cimento, fornecidas pelo ensaio de arrancamento, envolvendo taliscas sem tratamento (TT) e com tratamento impermeabilizante (AA) nas profundidades de ancoragem de 10, 20 e $30 \mathrm{~cm}$. Para cada profundidade de ancoragem $(10,20$ e $30 \mathrm{~cm})$ e cada tratamento (TT e AA) foram realizadas três repetições.

Cada gráfico apresenta as curvas tensão vs deformação para as diferentes profundidades de ancoragem (10, 20 e 30 $\mathrm{cm})$ relacionadas aos tratamentos (TT e AA), com três repetições (1, 2 e 3$)$.

Para as curvas referentes ao tratamento testemunha (TT) nas profundidades de ancoragem de 20 e de $30 \mathrm{~cm}$, são apresentadas apenas duas repetições, pois houve perda de corpos-de-prova devido à quebra de exemplar (30TT2) ou a problemas de leitura no relógio comparador (20TT1).

Constatou-se que as taliscas com tratamento asfáltico tiveram deslocamentos superiores, em relação ao solo-cimento, que as taliscas que não receberam tratamento impermeabilizante. Esta diferença é ainda mais significativa na profundidade

Tabela 2. Força de arrancamento $(\mathrm{N})$ e respectivo desvio-padrão das taliscas de bambu encravadas em solo-cimento

\begin{tabular}{|c|c|c|c|c|}
\hline \multirow{3}{*}{ Tratamentos } & \multicolumn{4}{|c|}{ Força de Arrancamento $(\mathrm{kN})$} \\
\hline & \multicolumn{3}{|c|}{ Profundidade de Ancoragem $(\mathrm{cm})$} & \multirow{2}{*}{ Média ${ }^{*}$} \\
\hline & 10 & 20 & 30 & \\
\hline Com asfalto & $7,300 \pm 1,217$ & $12,700 \pm 2,762$ & $11,200 \pm 400$ & $10,400 \pm 2,854 b$ \\
\hline Sem asfalto & $8,277 \pm 586$ & $16,400 \pm 2,227$ & $12,700 \pm 2,404$ & $12,425 \pm 4,068 \mathrm{a}$ \\
\hline Média & $7,783 \pm 1,005 \mathrm{c}$ & $14,550 \pm 3,024 \mathrm{a}$ & $11,800 \pm 1,483 b$ & \\
\hline
\end{tabular}


A.
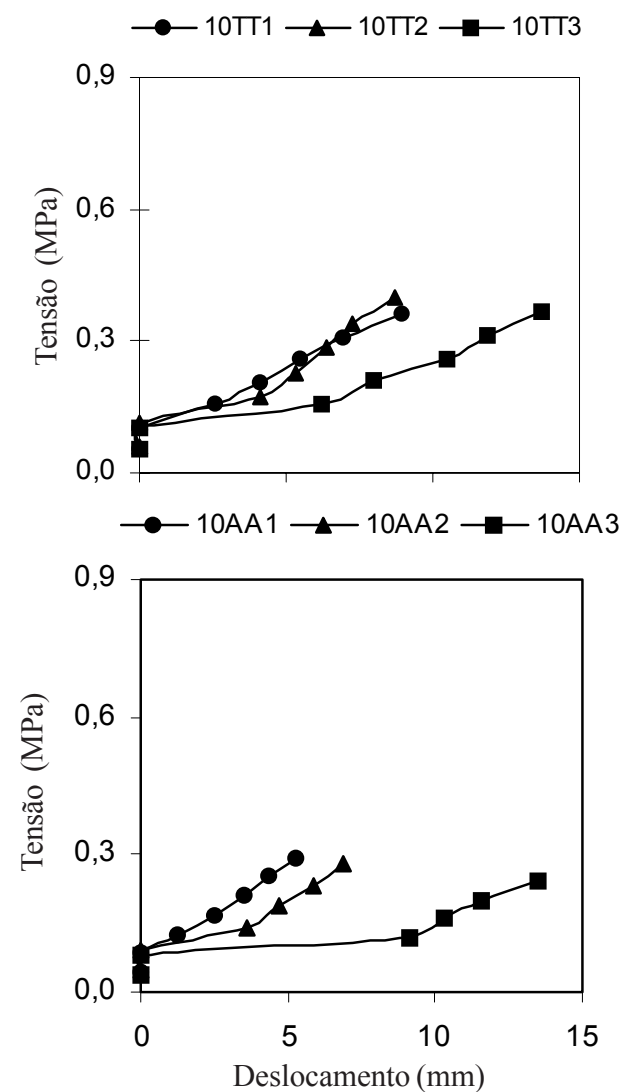

B.
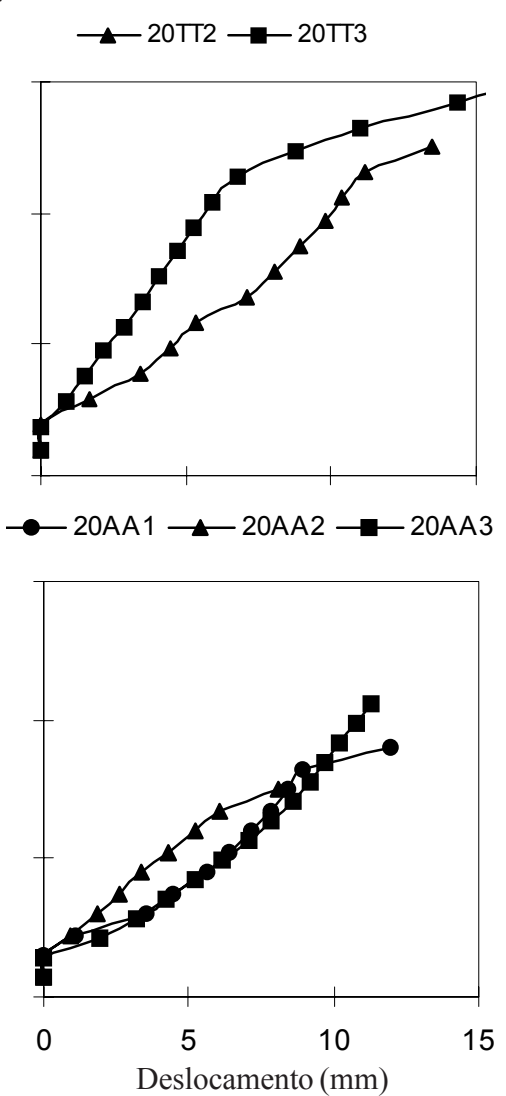

C.
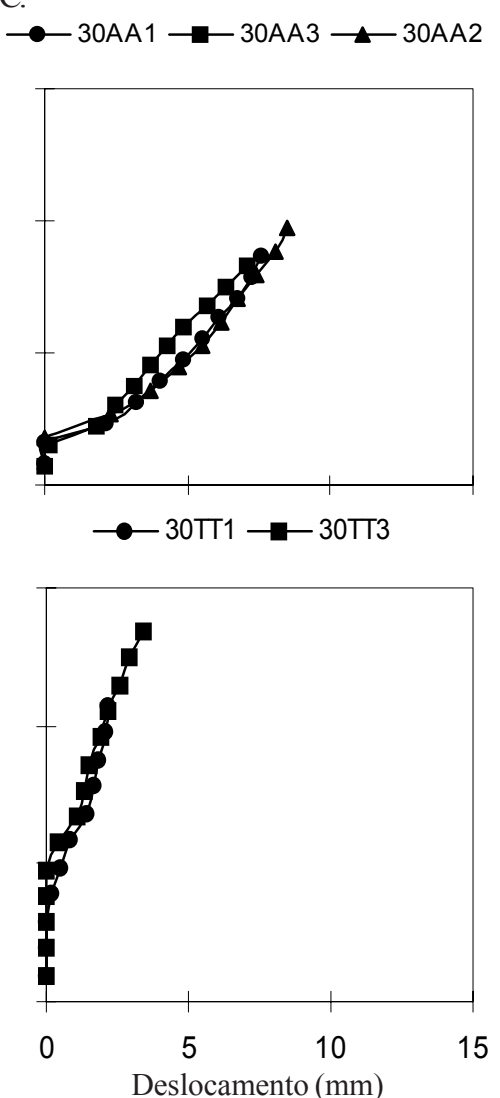

Figura 3. Curvas de "tensão vs deslocamento" para o ensaio de arrancamento, para os tratamentos sem asfalto (TT) e com asfalto (AA) na profundidade de ancoragem de 10 (A), 20 (B) e 30 (C) cm

de $30 \mathrm{~cm}$, como pode ser visto na Figura 3C, na qual o deslocamento não ultrapassou $3 \mathrm{~mm}$, em razão de ter ocorrido ruptura das taliscas no nó.

Os dados referentes à resistência ao arrancamento (em $\mathrm{MPa})$ e à força de arrancamento (em N) das taliscas de bambu encravadas no solo-cimento, para o ensaio de empuxamento, estão apresentados na Tabela 3.

Tabela 3. Resistência ao empuxamento e força de empuxamento, com respectivos desvios-padrões em ensaio de empuxamento, de taliscas de bambu encravadas em solo-cimento*

\begin{tabular}{lcc}
\multicolumn{1}{c}{ Tratamentos } & $\begin{array}{c}\text { Resistência ao } \\
\text { Empuxamento (MPa) }\end{array}$ & $\begin{array}{c}\text { Força de } \\
\text { Empuxamento }(\mathrm{N})\end{array}$ \\
\hline Sem asfalto (TT) & $1,81 \pm 0,32 \mathrm{a}$ & $10,100 \pm 0,1852 \mathrm{a}$ \\
Com asfalto (AA) & $1,38 \pm 0,16 \mathrm{a}$ & $9,267 \pm 0,896 \mathrm{a}$ \\
\hline * Médias, na mesma coluna, seguida da mesma letra, não diferem estatisticamente pelo teste de \\
Tukey $(\mathrm{p}>0,05)$
\end{tabular}

No ensaio de empuxamento, os resultados encontrados mostraram que não houve diferença significativa $(p>0,05)$ da resistência ao arrancamento, entre as taliscas tratadas com emulsão asfáltica mais areia $(1,81 \mathrm{MPa})$ e as que não receberam tratamento (1,38 MPa); não ocorreu, também, diferença significativa entre as forças aplicadas para os dois tratamentos, que foram de $10,100 \mathrm{~N}$ para as taliscas sem tratamento impermeabilizante e de 9,267 $\mathrm{N}$ para aquelas que receberam tratamento de emulsão asfáltica mais areia.

A Figura 4 apresenta as curvas de tensão vs deslocamento de taliscas de bambu, encravadas em corpos-de-prova de solo- cimento, para os dois tratamentos com asfalto e sem asfalto, do ensaio de empuxamento.

Os resultados dos dois ensaios estão em consonância com os relatados por Lima Jr. et al. (1996) que concluíram ser o bambu, em estado natural, o que apresenta maior resistência ao deslizamento, estando o mau desempenho do tratamento asfalto mais areia associado ao cisalhamento do material impermeabilizante. Sob o ponto de vista do aumento de aderência, Argolo Ferrão \& Freire (1995) não encontraram valores estatisticamente diferentes entre os vários tratamentos aplicados às taliscas de bambu, encravadas em concreto, independentemente do tratamento aplicado ou da profundidade de ancoragem adotada.

No entanto, Salgado (2000) observou que a extração de uma talisca de bambu tratada com alcatrão e areia, encravada em corpo-de-prova de concreto, exige maior força de arrancamento que as taliscas sem qualquer tratamento físico ou tratadas apenas com ranhuras na casca. $\mathrm{O}$ autor salientou, ainda, que a camada de alcatrão não deve ser muito espessa, para não prejudicar a aderência ao concreto, quando submetido a uma força de arrancamento.

Acredita-se que, no ensaio acima citado, se tenha conseguido uma película mais fina para o revestimento da talisca devido, talvez, à própria característica do material empregado ou à maneira como foi aplicado, o que evitou que o material de impermeabilização se rompesse obtendo-se, desta forma, melhor aderência. 

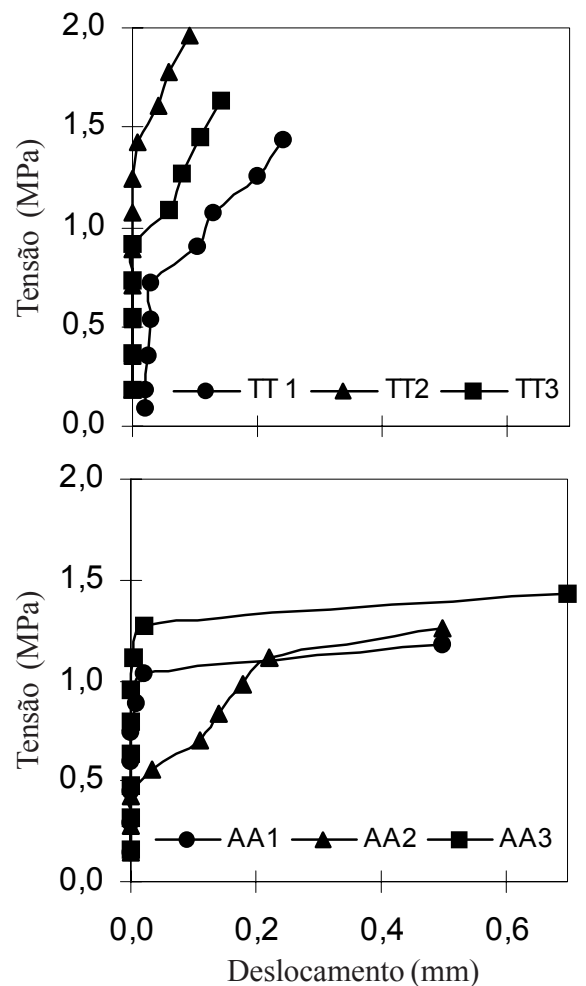

Figura 4. Curvas tensão vs deformação do ensaio de empuxamento, para os tratamentos sem asfalto (TT) e com asfalto (AA) de taliscas de bambu encravadas em solo-cimento

Para o ensaio de arrancamento, o tratamento das taliscas com emulsão asfáltica salpicada com areia grossa apresentou efeito negativo sobre a resistência de aderência das taliscas de bambu encravadas no solo-cimento. Os valores decrescentes de resistência ao arrancamento, inversamente proporcionais às profundidades de ancoragem, mostraram que, muito provavelmente, as taliscas de bambu tratadas com emulsão asfáltica salpicada com areia grossa, mobilizaram pequenas tensões de aderência, rompendo por cisalhamento o vínculo entre a areia e a emulsão asfáltica facilitando, assim, o deslocamento da talisca no ensaio de arrancamento.

\section{CONCLUSÕES}

1. O tratamento das taliscas de bambu com emulsão asfáltica mais areia apresentou efeito negativo sobre a resistência de aderência do bambu com a matriz de solo-cimento, reduzindo seu valor, aproximadamente, à metade.

2. O tratamento impermeabilizante aplicado as taliscas de bambu não interferiu na resistência à aderência desse material com a matriz de solo-cimento, na qual estavam encravadas.

3. A resistência de aderência obtida no ensaio de arrancamento para os tratamentos sem e com asfalto, foi inferior à resistência de aderência obtida no ensaio de empuxamento, para taliscas em estado natural e taliscas tratadas com emulsão asfáltica mais areia grossa.

4. De modo geral, o ensaio de arrancamento é mais adequado que o ensaio de empuxamento para a avaliação da aderência de taliscas de bambu encravadas em matriz de solo-cimento.

5. Taliscas de bambu, sem tratamento asfáltico, podem ser usadas encravadas em matrizes de solo-cimento, em vez de taliscas tratadas, por ser aquele procedimento de mais fácil utilização e de maior praticidade.

\section{AGRADECIMENTOS}

À Fundação de Amparo à Pesquisa do Estado de São Paulo (FAPESP) pelo apoio financeiro a esta pesquisa.

\section{LITERATURA CITADA}

ABNT - Associação Brasileira de Normas Técnicas. NBR11578 Cimento portland composto especificação, Rio de Janeiro. 1991. 8p.

Argollo Ferrão, A.M; Freire, W.J. Aderência entre bambu e concreto: teste de arrancamento com taliscas de Bambusa tuldoides. In: Encontro Brasileiro em Madeiras e em Estruturas de Madeira, 5, 1995, Belo Horizonte. Anais...Belo Horizonte: IBRAMEM, v.2, p.389-398. 1995.

Beraldo, A.L. Bambucreto - o uso do bambu como reforço do concreto. In: Congresso Brasileiro de Engenharia Agrícola, 16, 1987, Jundiaí. Anais... Jundiaí, SP: SBEA, 1987, v.2, p.521-530.

Geymayer, H.G.; Cox, F.B. Bamboo reinforced concrete. Journal of the American Concrete Institute, v. 67, n. 10, p.841-846, 1970

Ghavami, K. Bambu: um material alternativo na engenharia. Engenharia n.492, p.23-27. 1992.

Ghavami, K; Hombeek, R.V. Mechanical properties and water-repellent treatment of bamboo. In: Latin American Symposium Rational Organization of Building Applied to Low Cost Housing. 1981, São Paulo. Proceedings... São Paulo, v.1, p.49-55. 1981.

Janssen, J.J.A. Building with bamboo. 2. ed. London: Intermediate Technology Publications, 1995.

Kurian, N.P.; Kalam, A.K. A. Bamboo reinforced soil-cement for rural use. Indian Concrete Journal. n. 51, p.382-389, 1977.

Leonhardt, F.; Mönnig, E. Construções de concreto. 1 ed. Rio de Janeiro: Editora Interciência Ltda. 1977. 305p.

Lima Jr., H.C.; Dalcanal, P.R.; Willrich, F.L.; Barbosa, N.P. Características mecânicas do bambu Dendrocalamus giganteus:: análise técnica e experimental. In: Sustainable construction into the next millenium environmentally, friendly and innovative cement based materials. 2000, João Pessoa. Proceedings... João Pessoa: Federal University of Paraiba and The University of Sheffield. 2000. p.394-406.

Lima Jr, H.C.; Xavier, A.C.; Toledo Filho, R.D.; Barbosa, N. P. Aderência bambu-concreto. In: Congresso de Engenharia Civil, II, 1986, Juiz de Fora. Anais...Juiz de Fora: Universidade Federal de Juiz de Fora. 1996. v.2. p.312-323.

Recht, C.; Wetterwald, M.F. Bamboos. London: B.T. Batsford Ltd. 1994. 128p.

Salgado, A.L. de B. Resistência a la extracción de astillas de bambu enclavadas en concreto. In: Sustainable construction into the next millenium environmentally, friendly and innovative cement based materials. 2000, João Pessoa. Proceedings... João Pessoa: Federal University of Paraiba and The University of Sheffield. 2000. p.407-412.

SAS - Statistical analysis system. SAS System for linear models. Cary: SAS Institute, 1986.211p.

Toledo Filho, R.D.; Barbosa, N.P. Aplicação de bambu e de fibras naturais nas construções rurais. In: Congresso Brasileiro de Engenharia Agrícola, 19, 1987, Piracicaba. Anais... Piracicaba: SBEA, 1990, v.1, p.81-91. 